\title{
STATUS E OFFICIUM: O USO DO DIREITO ROMANO NOS COMENTÁRIOS ÀS SENTENÇAS DE TOMÁS DE AQUINO
}

Status and officium: The use of Roman law in The Commentary on the Sentences of Thomas Aquinas

Alfredo Storck *

Resumo: O presente artigo busca apresentar o uso que faz Tomás de Aquino do par conceitual: status e officium. Tomaremos como ponto de partida a distinção entre os pensamentos político antigo e moderno proposta pelo padre Lima Vaz. Em seguida, baseado no modo como ele interpreta Tomás de Aquino, procuraremos chamar a atenção para a presença do vocabulário jurídico romano na obra do Doctor Communis, em particular nos Comentários às Sentenças. Para isso, faremos algumas observações sobre o vocabulário transmitido pelo Digesto e pelas Institutas. Em seguida, veremos como Tomás de Aquino interpreta e utiliza esse vocabulário.

Palavras-chave: Tomás de Aquino. Aristóteles. Corpus Iuris Ciuilis. Status. Officium.

Abstract: This study presents Thomas Aquinas's use of a conceptual pair: status and officium. Our starting point will be the distinction between the ancient and modern political thought proposed by Father Lima Vaz. Then, based on his own interpretation of Thomas Aquinas, we will try to emphasize the presence of Roman legal vocabulary in the work of the Doctor Communis, particularly in the

* Professor titular do Departamento de Filosofia da UFRGS e pesquisador do CNPq. Artigo recebido em 28/02/2021 e aprovado para publicação em 29/02/2021. 
Commentary on the Sentences and make some observations on the vocabulary transmitted by the Digest and the Institutes. Finally, we will see how Thomas Aquinas interprets and uses this vocabulary.

Keywords: Thomas Aquinas. Aristotle. Corpus Iuris Ciuilis. Status. Officium.

\section{Introdução}

$\mathrm{N}$ o capítulo IV intitulado Ética e Direito da obra Escritos de Filosofia $I I^{1}$, Lima Vaz procura apresentar a oposição entre as concepções de Direito natural clássico e moderno sustentando que ambas expressam um certo tipo de universalidade. A concepção universalista clássica teria a forma nomotética e encontraria seu fundamento em "uma ordem do mundo que se supõe manifesta e na qual o nómos ou a lei da cidade é o modo de vida do homem que reflete a ordem cósmica contemplada pela razão." ${ }^{2}$ Nesse caso, a ontologia antiga proporcionaria ao domínio político conservar uma intrínseca relação com a ética, relação essa tornada extrínseca e problemática pelo advento do pensamento científico moderno. A modernidade operaria, a seu turno, com uma concepção de universalidade hipotética, vale dizer, fundada em algo oculto e que "requer uma explicação a título de hipótese inicial não verificada empiricamente e que deve ser confirmada dedutivamente pelas suas consequências". ${ }^{3} \mathrm{O}$ movimento de transformação que levou ao surgimento da modernidade estaria associado a uma "nova concepção do homem elaborada segundo as categorias da filosofia racionalista e da sua derivação empirista, e que fornecerá os traços para a nova imagem do indivíduo delineada nas novas teorias morais e políticas". ${ }^{4} \mathrm{Na}$ visão de Lima Vaz, se a modernidade aponta para uma "nova ideia de Razão" e uma "nova imagem do homem", isso ocorre porque antiguidade e modernidade possuem, em última instância, concepções antagônicas sobre o conceito de Natureza.

Nosso objetivo com esse artigo não é o de investigar o pensamento político moderno e a chamada "solução analiticamente satisfatória ao problema da associação dos indivíduos" a qual, aos olhos do autor, estaria ligado ao cartesianismo. ${ }^{5}$ Deixaremos igualmente intocada a caracterização de ambos

\footnotetext{
${ }^{1}$ LIMA VAZ, Henrique C. Escritos de Filosofia II. Ética e Cultura. São Paulo: Editora Loyola, $3^{a}$ Edição, 2000, p. 135-180.

${ }^{2}$ Idem, p. 146.

${ }^{3}$ Ibid., p. 146-147.

${ }^{4}$ Ibid., p. 161-162.

${ }^{5}$ Ibid., p. 163. Sobre a interpretação de Lima Vaz acerca da noção moderna de indivíduo e o papel desempenhado pelo cartesianismo, veja-se: LANDIM FILHO, Raul. "A questão do fundamento na aurora da consciência histórica moderna". Sintese Nova Fase, Belo Horizonte, v. 18, n. 55. p. 483-490, out./dez. 1991.
} 
os períodos históricos proposta por Lima $\mathrm{Vaz},{ }^{6}$ evitando com isso tomar aqui posição sobre a ou as fundações do mundo moderno. ${ }^{7}$ Tampouco buscaremos analisar, de um ponto de vista mais geral e sistemático, as relações entre Direito e Ética constantes no pensamento de Lima Vaz. ${ }^{8}$ De modo bastante mais limitado, articularemos nossa contribuição na forma de comentários inspirados pela seguinte afirmação:

"As complexas e delicadas relações que se estabelecem entre a consciência e a lei irão constituir um capítulo clássico da Ética cristã e um dos temas fundamentais da releitura, por parte dos teólogos cristãos, da teoria estóica do Direito Natural. Essas relações ou a sua correta formulação serão um dos fios condutores da assimilação da Ética aristotélica por Tomás de Aquino e da sua tentativa de reinterpretação das concepções políticas de Aristóteles no contexto histórico do mundo medieval-cristão. A estrutura teonômica da universalidade objetiva da physis - já presente no Estoicismo e no neoplatonismo - encontra uma formulação sistemática e definitiva na teologia de Sto. Tomás pela proposição de um teocentrismo rigoroso, fundado na transcendência absoluta do Deus Criador, que estende seu influxo ordenador à realidade política. Na síntese tomista, anunciam-se, no entanto,

${ }^{6}$ A temática recebeu particular atenção no século passado. De um lado, encontramos autores e autoras que, mesmo partindo de posições aparentemente antagônicas, procuram apontar as perdas produzidas pela modernidade por referência ao pensamento clássico. É o caso, para o direito, de: STRAUSS, Leo. Natural Right and History. Chicago: University of Chicago Press, 1965 e VILLEY, Michel. La Formation de la pensée juridique modern. Paris: PUF, 2e éd., 2003, VILLEY, Michel. Questions de saint Thomas sur le droit et la politique. Paris: PUF, 1987; para a filosofia moral: ANSCOMBE, Gertrude Elizabeth Margaret. "Modern Moral Philosophy". In: Ethics, Religion and Politics (The Collected Philosophical Papers of G. E. M. Anscombe, Volume 3). Minneapolis: University of Minnesota Press, 1981, p. 26-42; para o pensamento político: ARENDT, Hannah. The Human Condition. Chicago: University of Chicago Press, 1958. De outro lado, e mais recentemente, encontramos leituras que concebem os dois momentos como menos radicalmente opostos: MÄKINEN, Virpi and KORKMAN, Petter (eds). Transformations in Medieval and Early-Modern Rights Discourse. Dordrecht: Springer, 2006; KRAYE, Jill and SAARINEN, Risto. Moral Philosophy on the Threshold of Modernity. Dordrecht: Springer, 2005. Lima Vaz cita Arendt, mas sua posição parece mais próxima da de HABERMAS, Jurgen. Teoria e Práxis. Estudos de Filosofia Social. Tradução e apresentação Rúrion Melo. São Paulo: UNESP, 2011.

7 A expressão é de SKINNER, Quentin. The Foundations of Modern Political Thought: Vol. 1. The Renaissance; Vol. 2: The Age of Reformation. Cambridge: Cambridge University Press, 1978. Para o significado e impacto da obra de Skinner, veja-se as contribuições recolhidas por: BRETT, Annabel and TULLY, James (eds). Rethinking The Foundations of Modern Political Thought. Cambridge: Cambridge University Press, 2006.

8 O tema tem sido objeto de diversos estudos, como é possível constatar na bibliografia indicada na página dedicada ao autor:_http://www.padrevaz.com.br/index.php/bibliografia/ bibliografia-completa/67-livros-e-artigos-sobre-lima-vaz (consulta em fevereiro de 2021). Destacamos: TOLEDO, Claudia. "Estrutura da relação entre a ética e direito no pensamento de Lima Vaz". Síntese, Belo Horizonte, v. 32, n. 102. p. 25-38. jan./abr. 2005; FERRAZ JR., Tercio Sampaio. "Ética e direito no pensamento de Henrique Vaz". In: PERINE, Marcelo (Org.). Diálogos com a cultura contemporânea: homenagem ao Pe. Henrique C. de Lima Vaz, SJ. São Paulo: Loyola, 2003. p. 71-86; MAC DOWELL, João A. “Ética e direito no pensamento de Henrique de Lima Vaz." Revista Brasileira de Direito Constitucional, n. 9, p. 237-273, jan./ jun. 2007 e PERINE, Marcelo. "A ética e a crise da modernidade: uma leitura a partir da obra de Henrique C. de Lima Vaz." Cadernos IHU Ideias, São Leopoldo, v. 5, p. 1-22, 2007. 
os problemas das relações entre sociedade política e sociedade religiosa que eram desconhecidos de Aristóteles e que acabaram por constituir o terreno de longas polêmicas preparadoras e antecipadoras das crises das concepções políticas clássicas que acompanha a formação do mundo moderno." ${ }^{9}$

A tese acima alinhavada ecoa uma interpretação bastante recorrente acerca do papel desempenhado pelo Doctor Angelicus na recepção do pensamento aristotélico. Sem questionar a influência desempenhada pelo estoicismo na incorporação da ética aristotélica, ${ }^{10}$ ou mesmo sua reconhecida presença entre as fontes do pensamento jurídico romano, ${ }^{11}$ gostaríamos de sugerir que os conceitos de natura e status, transmitidos pelo Corpus Iuris Ciuilis, em particular pelo Digesto e pelas Institutas, desempenharão papel não negligenciável na "reinterpretação das concepções políticas de Aristóteles". Não foram apenas as relações entre "a consciência e a lei" que mereceram atenção da parte de Tomás. A noção jurídica de pessoa, acompanhada dos tipos de potestas que estruturam o ordenamento jurídico, configurarão a base empregada pelo Doctor Universalis para pensar as obrigações no interior da Igreja cristã.

Obviamente, ao discorremos sobre a noção de natureza, não buscaremos nos aventurar nos meandros e complexidades da teoria tomásica da lei natural, tema amplamente discutido na literatura especializada. ${ }^{12}$ Nosso objetivo é mais simples. Primeiramente, chamaremos a atenção para o vocabulário transmitido pelo Digesto e pelas Institutas. Em seguida, procuraremos mostrar como Tomás de Aquino assimila esse vocabulário em sua obra, em particular nos Comentários às Sentenças de Pedro Lombardo.

\section{As fontes romanas}

Em um estudo que persegue as origens filosóficas da doutrina moderna acerca dos contratos, o historiador do Direito James Gordley encontra em Tomás de Aquino um momento decisivo na assimilação do Direito Romano

\footnotetext{
${ }^{9}$ LIMA VAZ, Henrique C. Escritos de Filosofia II, p. 160-161.

${ }^{10}$ Sobre isso, consulte-se: VERBEKE, Gerard. The Presence of Stoicism in Medieval Thought. Washington: Catholic University of America Press, 1983.

${ }^{11}$ VANDER WAERDT, Paul A. "Philosophical Influence on Roman Jurisprudence? The Case of Stoicism and Natural Law". In: HAASE, Wolfgang und TEMPORINI, Hildegard (eds). Aufstieg und Niedergang der römischen Welt / Rise and Decline of the Roman. Berlin: De Gruyter, vol II.36.6, 1993, p. 4851-4900.

${ }_{12}$ Para as principais tendências interpretativas acerca da teoria da lei natural, consulte-se: MCINERNY, Ralph. Ethica Thomistica: The Moral Philosophy of Thomas Aquinas, Washington: Catholic University of America Press, 1997; FINNIS, John, Aquinas: Moral, Political and Legal Theory, Oxford and New York: Oxford University Press, 1998. LISSKA, Anthony J. Aquinas's Theory of Natural Law: An Analytic Reconstruction, Oxford: Oxford University Press, 1998. RHONHEIMER, Martin, Natural Law and Practical Reason: A Thomist View of Moral Autonomy, New York: Fordham University Press, 2000.
} 
durante o período medieval. ${ }^{13} \mathrm{O}$ direito praticado em Roma e transmitido pela compilação realizada sob o patrocínio do Imperador Justiniano trazia consigo uma das características centrais do pensamento jurídico romano: a carência de conceitos gerais que estruturassem e definissem os diversos tipos de contratos. Não que os juristas romanos deixassem de interpretar os dispositivos legais e os conceitos especificamente jurídicos neles presentes. Ocorre apenas que o método interpretativo empregado evitava a apresentação de definições gerais. Preferiam antes o método de aplicação dos conceitos a casos específicos, ou seja, a casos que, mesmo raros, forneceriam a oportunidade para refinar conceitos jurídicos. Evitam assim o caminho de definições gerais que poderiam dar a impressão de serem aplicáveis a todos os casos. ${ }^{14}$ Cumpre observar, no entanto, que a sistematicidade ausente no Direito Romano se encontra presente nas doutrinas modernas acerca do contrato. Isso significa, para o historiador, a tarefa de determinar quando o conjunto de regras e dispositivos particulares presentes no Corpus Iuris Ciuilis, acompanhado de poucas máximas gerais e desprovidas de sistematicidade, passou a contar como uma verdadeira doutrina sistemática acerca dos contratos.

Segundo a tese avançada por Gordley, coube a Tomás de Aquino inaugurar a tendência sistematizadora. ${ }^{15}$ Isso teria ocorrido por meio da aplicação dos princípios aristotélicos concebidos para a explicação da virtude ao âmbito da lei moral. Ao discutir as exigências para uma promessa ser vinculante, o Aquinate teria observado ser a promessa a expressão seja de um ato de liberalidade, seja de justiça comutativa. Mostrou, na sequência, como contratos particulares, como a compra e venda, poderiam ser definidos desde que satisfeitas duas condições: sua classificação como um dos dois tipos de atos acima elencados e a identificação da finalidade para a qual cada instrumento contratual se destina. Dito de um modo um pouco mais específico, Tomás explicaria não apenas a razão de ser justo o cumprimento de uma promessa, mas acrescentaria igualmente a obrigatoriedade de seu comprimento. Partia, assim, da teoria aristotélica da virtude para alcançar a teoria da lei moral, concluindo ser um preceito da lei natural a obrigação de cumprir o prometido. ${ }^{16}$

\footnotetext{
${ }^{13}$ GORDLEY, James. The Philosophical Origins of Modern Contract Doctrine. Oxford: Clarendon University Press, $2^{\text {nd }}$ edition, 2011.

${ }^{14}$ Para uma caracterização mais acurada do método empregado pelos juristas romanos, veja-se: GORDLEY, James. The Jurists: A Critical History. Oxford: Oxford University Press, 2013, p. 7-12. ${ }^{15}$ Ultrapassa o escopo desse artigo apresentar os momentos históricos sucessivos pelos quais, na visão de Gordley, teria passado a teoria dos contratos, desde a antiguidade até a contemporaneidade. Limitar-nos-emos a apontar a continuidade da interpretação de Gordley na obra de DECOCK, Wim. Theologians and Contract Law: The Moral Transformation of the Ius Commune (Ca. 1500-1650). Nijhoff: Brill, 2012.

${ }_{16}$ Os demais detalhes da tese podem ser encontrados no capítulo 2 (Aristotle and Thomas Aquinas) da obra The Philosophical Origins of Modern Contract Law, p. 10-29.
} 
Tomando por apoio a tese de Gordley, poderemos indagar pelo efeito contrário, vale dizer, pela influência que o Direito Romano teria exercido na interpretação do aristotelismo professado pelo Doctor Comumnis. Para tanto, coloquemos inicialmente em evidência algumas das teses presentes no Digesto para, na sequência, olhá-las da perspectiva proposta por Tomás de Aquino.

O Livro I do Digesto ${ }^{17}$, após apresentar as noções centrais de direito (ius) e justiça (iustitia), ${ }^{18}$ caracteriza as fontes do direito e os tipos de leis empregadas na legislação romana. Todavia, com respeito às fontes do direito, é possível constatar-se uma importante ambiguidade concernindo, justamente, a noção de natureza, ou melhor, a de direito natural. Por um lado, tem-se uma divisão bipartite, retirada das Institutas de Gaio, que toma o direito natural e o direito dos povos como sinônimos, precisando apenas ser o ius gentium aquele que a razão natural (ratio naturalis) institui entre todos os seres humanos..$^{19}$ Por outro, tem-se uma concepção tripartite, atribuída ao jurista Ulpiano, que distingue claramente entre direito natural (ius naturale), direito dos povos (ius gentium) e direito civil. ${ }^{20}$ Independentemente da origem ou correção de ambas as divisões, ${ }^{21}$ importa-nos salientar aqui o

${ }^{17}$ CORPUS IURIS CIUILIS, editio stereotypa quinta, Volumen Primum: INSTITUTIONES, recognovit Paulus Krueger, DIGESTA, recognovit Theosorus Mommsen. Berlin, 1868. Para a tradução inglesa: THE DIGEST OF JUSTINIAN. Translation edited by Alan Watson. Philadelphia: University of Pennsylvania Press, 4 vols., 1985. DIGESTO ou Pandectas do imperador Justiniano. Tradução de Eduardo Cesar Silveira Vita MARCHI et alii. São Paulo: Yk Editora, vol. 1, 2017.

${ }^{18}$ D. 1.1.1: "pr. Iuri operam daturum prius nosse oportet, unde nomen iuris descendat. est autem a iustitia appellatum: nam, ut eleganter Celsus definit, ius est ars boni et aequi." Posteriormente, será a apresentada a famosa definição de Ulpiano: D. 1.1.10: "pr. Iustitia est constans et perpetua voluntas ius suum cuique tribuendi. 1. Iuris praecepta sunt haec: honeste vivere, alterum non laedere, suum cuique tribuere. 2. Iuris prudentia est divinarum atque humanarum rerum notitia, iusti atque iniusti scientia." A definição do jurista Celsus é retomada por Tomás de Aquino na Suma de Teologia, II-II, q. 57, a. 1, primeira objeção (Doravante, a obra será referida apenas como S.T.) Já a definição de Ulpiano é abordada em detalhe na S.T., II-II, q. 58, a.1 e lida com base na teoria das virtudes de Aristóteles. Sobre a presença do Corpus Iuris Ciuilis na obra de Tomás, veja-se: AUBERT, Jean-Marie. Le droit romain dans l'oeuvre de de saint Thomas. Paris: Vrin, 1955.

${ }^{19}$ D. 1.1.9: “Omnes populi, qui legibus et moribus reguntur, partim suo proprio, partim communi omnium hominum iure utuntur. Nam quod quisque populus ipse sibi ius constituit, id ipsius proprium civitatis est vocaturque ius civile, quasi ius proprium ipsius civitatis: quod vero naturalis ratio inter omnes homines constituit, id apud omnes peraeque custoditur vocaturque ius gentium, quasi quo iure omnes gentes utuntur."

${ }^{20}$ D. 1.1.2: "Privatum ius tripartitum est: collectum etenim est ex naturalibus praeceptis aut gentium aut civilibus."

${ }^{21}$ A temática é tradicionalmente discutida na literatura. Um rápido estado da questão pode ser encontrado em: KROGER, John R. "The Philosophical Foundations of Roman Law: Aristotle, the Stoics and Roman Theories of Natural Law." In BROOKS, Richard O. (ed.) Cicero and Modern Law. New York: Routledge, 2016, p. 229-268. Consulte-se ainda: CARTAXO, Ernani Quarita. “O conceito clássico e post-clássico do jus naturale e do jus gentium." Revista da Faculdade de Direito, UFPR, v. 1, 1953, p. 26-47 e STORCK, A. C. "Natureza e Direito nas Institutas de Gaio." Philósophos, v. 16, n. 1, 2011, p. 13-33. 
fato dos textos apontarem para concepções distintas de natureza. Por um lado, na visão da Gaio, os dispositivos do direito natural estariam ligados à racionalidade humana, ao passo que, para Ulpiano, o ser humano compartilharia com os demais animais comportamentos naturais, como a conjunção entre macho e fêmea para a reprodução e o cuidado com a prole. Os dispositivos do direito natural, na formulação de Ulpiano, seriam distintos daqueles próprios ao mundo humano, ou direito dos povos, por serem esses presentes em toda forma de associação humano. ${ }^{22}$ Em seguida, o Digesto passa a elencar, novamente com base nas Institutas de Gaio, as três matérias centrais do direito privado: pessoas, coisas e ações. ${ }^{23}$ Quanto às pessoas, uma primeira divisão caracteriza-as conforme o status ${ }^{24}$ e por relação à liberdade (status liberatis), entendida como a faculdade natural (naturalis facultas) de fazer aquilo que se queira, salvo se houver impedimentos decorrentes da força ou de proibição jurídica. ${ }^{25}$ Há, portanto, dois tipos de pessoas: homens livres e escravos. ${ }^{26}$ A primeira condição é dupla. Ou se nasce livre (ingenuus), por ter nascido de uma mulher livre, ${ }^{27}$ ou se é liberto (libertinus), por ter recebido a liberdade por um ato de manumissão. ${ }^{28} \mathrm{~A}$ condição de escravo (servus) é uma só, havendo diferenças na forma como essa condição foi constituída. Pelo direito civil, próprio à Roma, alguém se torna escravo quando, maior de vinte anos, admite ser vendido. Pelo direito dos povos (ius gentium), se foi capturado em uma guerra ou se nasceu de uma mulher escrava. ${ }^{29}$ Como veremos, a caracterização da escravidão como instituída pelo direito dos povos constituirá um dos pontos fulcrais da interpretação proposta por Tomás de Aquino. Por aceitar, na esteira do Digesto, a escravidão como uma condição instituída pelo direito positivo e, portanto, como algo não natural e mesmo contrário à natureza (contra naturam), ${ }^{30}$ Tomás não poderá endossar completamente a teoria aristotélica acerca da escravidão natural o que lhe levará a reinterpretar a própria noção aristotélica de natureza.

${ }^{22}$ D. 1.1.1.3: “Ius naturale est, quod natura omnia animalia docuit: nam ius istud non humani generis proprium, sed omnium animalium, quae in terra, quae in mari nascuntur, avium quoque commune est. Hinc descendit maris atque feminae coniunctio, quam nos matrimonium appellamus, hinc liberorum procreatio, hinc educatio: videmus etenim cetera quoque animalia, feras etiam istius iuris peritia censeri."

${ }^{23}$ D. 1.5.1: "Omne ius quo utimur vel ad personas pertinet vel ad res vel ad actiones."

${ }^{24}$ Sobre o significado da expressão, consulte-se: BERGER, Adolf. Encyclopedic Dictionary of Roman Law. Philadelphia: The American Philosophical Society, 1953, p. 714-715.

${ }^{25}$ D. 1.5.4. "pr. Libertas est naturalis facultas eius quod cuique facere libet, nisi si quid vi aut iure prohibetur."

${ }^{26}$ D. 1.5.3: "Summa itaque de iure personarum divisio haec est, quod omnes homines aut liberi sunt aut servi."

${ }^{27}$ D. 1.5.5.2: "Ingenui sunt, qui ex matre libera nati sunt."

${ }^{28}$ D. 1.5.6: "Libertini sunt, qui ex iusta servitute manumissi sunt."

${ }^{29}$ D. 1.5.5.1: "Servi autem in dominium nostrum rediguntur aut iure civili aut gentium: iure civili, si quis se maior viginti annis ad pretium participandum venire passus est. Iure gentium servi nostri sunt, qui ab hostibus capiuntur aut qui ex ancillis nostris nascuntur." ${ }^{30}$ D. 1.5.4.1: "Servitus est constitutio iuris gentium, qua quis dominio alieno contra naturam subicitur." 
O Digesto opera ainda com uma segunda divisão das pessoas, essa fundada não mais na noção de liberdade, mas na de poder (potestas). ${ }^{31} \mathrm{Em}$ primeiro lugar, estão sob o poder (in potestate) os escravos, de tal sorte que o direito dos povos confere ao senhor (dominus) o poder de vida e de morte sobre os escravos e atribui tudo o que é adquirido pelo escravo como pertencendo ao senhor. ${ }^{32} \mathrm{O}$ escravo romano, reduzido à condição de propriedade do senhor, acaba por perder toda personalidade jurídica, passando a ser uma pessoa (persona) sem direitos e, no limite, uma coisa (res). ${ }^{33}$ A relação de poder estrutura também a unidade familiar romana, na medida em que o status familiae, ou seja, a posição ocupada na esfera familiar caracteriza as pessoas como independentes (sui iuris) ou sujeitas ao poder de outrem (alieni iuris) e essa última posição jurídica influencia a própria condição de cidadania romana. $\mathrm{O}$ ápice da hierarquia é ocupado pelos patres familiarum, visto como aqueles que estão apenas sobre o seu próprio poder (sunt suae potestatis). Normalmente são os membros mais velhos da família e desfrutam do maior número de direitos e capacidades que a cidadania romana oferece. O poder do chefe da família (patria potestas) é exercido sob as demais pessoas que compõem a estrutura familiar, sendo essas pessoas vistas como alieni iuris. A posição da mulher cidadã romana é ambígua. Mater familias é a mulher que não está sob o poder de outro, mas é filia familias a mulher que, mesmo casada (uxor in manu), está sob o poder de outro, seja do marido ou do pater famílias. Está ainda sob o poder do pater familias toda a sua descendência (filhas e filhos, legítimos ou adotados) ${ }^{34}$ sob a qual é exercido, ao menos teoricamente, um poder ilimitado que lhe autoriza a matar (direito de vida e morte - ius vitae necisque), vender como escravos e abandonar. ${ }^{35}$

\footnotetext{
${ }^{31}$ D. 1.5.5: "pr. De iure personarum alia divisio sequitur, quod quaedam personae sui iuris sunt, quaedam alieno iuri subiectae sunt." Para os diversos sentidos de potestas, veja-se BERGER, Adolf. Op. cit, p. 641.

${ }^{32}$ D. 1.6.1.1: "Igitur in potestate sunt servi dominorum (quae quidem potestas iuris gentium est: nam apud omnes peraeque gentes animadvertere possumus dominis in servos vitae necisque potestatem fuisse) et quodcumque per servum adquiritur, id domino adquiritur." ${ }^{33} \mathrm{O}$ Digesto parece oscilar e caracteriza o servus ora como pessoa, ora como coisa. O significado dessa oscilação é tema de frequente debate entre romanistas. Sobre isso, veja-se, dentre outros: BUCKLAND, William Warwick. The Condition of the Slave in Private Roman Law from Augustus to Justinian. Cambridge: Cambridge University Press, 1970.

${ }^{34}$ D. 1.6.4: “Nam civium Romanorum quidam sunt patres familiarum, alii filii familiarum, quaedam matres familiarum, quaedam filiae familiarum. Patres familiarum sunt, qui sunt suae potestatis sive puberes sive impuberes: simili modo matres familiarum; filii familiarum et filiae, quae sunt in aliena potestate. Nam qui ex me et uxore mea nascitur, in mea potestate est: item qui ex filio meo et uxore eius nascitur, id est nepos meus et neptis, aeque in mea sunt potestate, et pronepos et proneptis et deinceps ceteri."

${ }^{35}$ Sobre a estrutura familiar romana, consulte-se: MOUSOURAKIS, George. Roman Law and the Origins of the Civil Law Tradition. New York, London: Springer, 2015; RIGGSBY, Andrew. Roman Law and the Legal World of the Romans. Cambridge: Cambridge University Press, 2010; LEWIS, Andrew. "Slavery, Family, and Status", in JOHNSTON, David (ed). The Cambridge Companion to Roman Law. Cambridge: Cambridge University Press, 2015, p. 151-174.
} 
A despeito de possuir precipuamente o direito privado como objeto e expressamente evitar abordar o direito público romano, ${ }^{36}$ o Livro I do Digesto introduz ainda a noção de officium. $\mathrm{O}$ vocábulo parece ter sido originalmente empregado para designar as relações familiares e de amizade expressando valores sociais e extrajurídicos. A noção de obrigação moral associada ao termo manifesta-se, no contexto do direito privado, por exemplo, na forma do mandatum e no sentimento de honra que um cidadão romano experimentava ao cuidar dos assuntos de outro cidadão. ${ }^{37} \mathrm{No}$ contexto do Livro I, o Digesto utiliza-o para marcar as obrigações ligadas a posições ocupadas por servidores públicos, como magistrados, senadores, pretores, cônsules etc. Assim, para dar outro exemplo, é officium do cônsul aconselhar quem deseja realizar um ato de manumissão. ${ }^{38}$

\section{As fontes romanas interpretadas}

Notemos, inicialmente, que o aparato legislativo romano era conhecido pelos medievais desde a segunda metade do século XI, sendo estudado nas universidades medievais, como a de Bolonha. A Política de Aristóteles, por seu turno, somente foi traduzida dois séculos mais tarde, por volta dos anos 1260, por Guilherme de Moerbeke. Isso significa que, anteriormente à recepção da Política, os autores medievais encontravam no Corpus Iuris Ciuilis os principais elementos para descrever a estrutura familiar e as relações hierárquicas de poder vigentes no interior dessa esfera. Serão, portanto, as relações familiares descritas pelo Digesto e pelas Institutas que empregará Tomás de Aquino no momento de descrever a condição das pessoas, os tipos de promessas que elas possuem legitimidade para realizar e os tipos de obrigações em que podem se engajar. A obra de Aristóteles que servirá de referência para Tomás nesse período será a Ética Nicomaqueia. ${ }^{39}$ Mesmo que ele escreva seu comentário a essa obra possivelmente apenas enquanto redigia a Secunda secundae da Suma de

\footnotetext{
${ }^{36}$ D. 1.1.1.2: "Huius studii duae sunt positiones, publicum et privatum. Publicum ius est quod ad statum rei Romanae spectat, privatum quod ad singulorum utilitatem: sunt enim quaedam publice utilia, quaedam privatim. Publicum ius in sacris, in sacerdotibus, in magistratibus constitit."

${ }^{37}$ D. 17. 1. 1. 4: "Mandatum nisi gratuitum nullum est: nam originem ex officio atque amicitia trahit, contrarium ergo est officio merces: interveniente enim pecunia res ad locationem et conductionem potius respicit." Sobre isso, veja-se ZIMMERMANN, Reinhard. The Law of Obligations. Roman Foundations of the Civilian Tradition. Cape Town: Juta \& Co. Ltd, 1992, p. 415-420.

${ }^{38}$ D. 1.10.1: "pr. Officium consulis est consilium praebere manumittere volentibus."

${ }^{39}$ Sobre a primeira recepção da Ética Nicomaqueia, em particular sobre o conceito de felicidade entre autores medievais, veja-se: BUFFON, Valeria. "Philosophers and Theologians on Happiness: An Analysis of Early Latin Commentaries on the Nicomachean Ethics". Laval théologique et philosophique, 60, 2004, p. 449-476.
} 
Teologia, ${ }^{40}$ a obra de Aristóteles já circulava, desde 1246/47 na tradução de Roberto Grosseteste ${ }^{41}$ e Tomás conhecia-a ainda através dos comentários de Averróis ${ }^{42}$ e de Alberto Magno, seu mestre. ${ }^{43}$ Assim, ainda que possua algumas semelhanças com a estrutura descrita por Aristóteles no Livro I da Política, a estrutura familiar que encontraremos nos Comentários às Sentenças de Pedro Lombardo ${ }^{44}$ será a da família romana transmitida pelos textos jurídicos (civilistas e canonistas) lida conjuntamente com as indicações presentes no livro VIII da Ética Nicomaqueia.

Não chega a ser surpreendente que Tomás de Aquino recorra aos textos jurídicos no momento de abordar a figura do matrimônio cristão. Afinal de contas, tratava-se, em certa medida, de posicionar o casamento cristão, entendido como sacramento, frente ao casamento jurídico de base romana concebido apenas como um contrato que produzia as relações de poder que acima elencamos. Ademais, quando Tomás escreve sobre o matrimônio nos seus Comentários às Sentença de Pedro Lombardo, o momento é de mudanças legislativas acerca do casamento. O canonista Raimundo de Pennaforte havia publicado a sua Summa de matrimonio (1235), ${ }^{45}$ obra que contribuiu decisivamente para que o matrimônio cristão passasse a ser visto como dotado de uma estrutura tridimensional. O casamento pertenceria ao direito natural na medida em que resultaria de uma disposição ou inclinação natural completada por uma decisão livre da vontade. $\mathrm{O}$ casamento possuiria igualmente uma dimensão contratual, precisamente aquela transmitida pelo direito civil romano, que o apresentava como um acordo realizado de forma livre e voluntária entre os cônjuges e que

\footnotetext{
${ }^{40}$ A data da composição das Sententia libri Ethicorum é objeto de debate entre os intérpretes. Para uma apresentação rápida das posições e para uma análise do comentário ao Livro $\mathrm{V}$, sobre a justiça, vide: PERKAMS, Matthias. "Aquinas's Interpretation of the Aristotelian Virtue of Justice and His Doctrine of Natural Law". In: BEJKZY, István P. Virtue Ethics in the Middle Ages. Commentaries on Aristotle's Nicomachean Ethics, 1200-1500. Leiden: Brill, 2008, p. 131-151. ${ }^{41}$ The Greek Commentaries on the Nicomachean Ethics of Aristotle in the Latin Translation of Robert Grosseteste, Bishop of Lincoln († 1253), ed. H. Paul F. Mercken. Leiden - Louvain: Brill: 1973. HILL, Kathryn D. "Robert Grosseteste and his work of Greek translation". Studies in Church History, 13, 1976, p. 213-222.

${ }^{42}$ AVERROES. Middle Commentary to the Nicomachean Ethics, ed. Jerzy B. Korolec, "Mittlerer Kommentar von Averroes zur Nikomachischen Ethik des Aristotles". Mediaevalia philosophica Polonorum, 31, 1992, p. 61-118.

${ }^{43}$ ALBERTUS MAGNUS. Super Ethica, ed. Wilhelm Kübel, Opera omnia. Münster, 1951. Sobre as fontes diretas e indiretas de Alberto e Tomás, veja-se: HOFFMANN, Tobias. "Albert the Great and Thomas Aquinas on Magnanimity". IN: BEJKZY, István, Op. Cit., p. 101-129.

${ }^{44}$ Sobre a evolução histórica do pensamento de Tomás de Aquino, consulte-se: TORRELL, Jean-Pierre. Saint Thomas Aquinas: Volume 1, The Person and His Work. Translated by Robert Royal. Washington: Catholic University of America, 1996. Para os Comentários às Sentenças, vide p. 39-47. Como é bem conhecido, Tomás não chegou a escrever a parte correspondente ao casamento na Suma de Teologia (Supl., Q. 41 a 68). O que consta ali é o trabalho dos secretários que se apoiaram nos Comentários às Sentenças para completar o percurso da Suma de Teologia. ${ }^{45}$ RAIMUNDUS DE PENNAFORTI, Summa on Marriage. Translated by P. Payer. Toronto: Pontifical Institute of Mediaeval Studies, 2005.
} 
definia as posições de cada pessoa no interior da família. Pertenceria, por fim, o casamento ao direito da Igreja cristã por ser contraído de forma indissolúvel entre cristãos batizados que ministrariam mutuamente esse sacramento, sem a necessidade da intervenção da Igreja. ${ }^{46}$

$\mathrm{O}$ artigo que abre a série de questões acerca da essência do casamento nos Comentários às Sentenças indaga pelo caráter natural do matrimônio. ${ }^{47}$ Tanto as objeções inicialmente apresentadas quanto os dois sed contra citados exploram dois significados distintos do que significa ser natural: o jurídico, presente na expressão 'direito natural' tal como conceituada por Ulpiano $^{48}$ e o de condição natural, presentes respectivamente em Cícero ${ }^{49}$, ao apresentar a condição humana inicial como de natureza silvestre, e na Ética Nicomaqueia, quando o Estagirita formula seu célebre dito segundo o qual o ser humano é, por natureza, mais afeito à vida conjugal do que à vida política. ${ }^{50} \mathrm{~A}$ dificuldade enfrentada por Tomás reside, nesse contexto, em fornecer uma interpretação para a noção de natura que torne possível apresentar elementos intrínsecos à natureza humana que, ao mesmo tempo em que permitem identificar diferentes estágios pelos quais passa essa natureza, apontem para diferentes obrigações a serem realizadas pelos seres humanos. Dito nos termos da resposta ao terceiro argumento, a natureza humana, diferentemente da divina, não é imóvel. Por conseguinte, o que pertence ao direito natural (ius naturale) deverá ser distinguido segundo os diversos status et conditiones dos seres humanos. A solução encontrada

\footnotetext{
${ }^{46}$ Sobre a evolução medieval do casamento cristão, consulte-se: GAUDEMET, Jean. Le mariage en Occident. Paris : Éditons du Cerf, 1987 ; REYNOLDS, Philip Lyndon. How Marriage Became one of the Sacraments. The Sacramental Theology of Marriage from its Medieval Origins to the Council of Trent. Cambridge: Cambridge University Press, 2016 e WITTE JR, John. From Sacrament to Contract. Marriage, Religion, and Law in Western Tradition. Louisville: John Knox Press, 2012.

${ }^{47}$ Sent. IV, q. 26, a. 1: "Utrum matrimonium sit naturale." Por razões de comodidade, mas também devido às restrições decorrentes da epidemia mundial de Covid-19, citaremos as obras de Tomás de Aquino seguindo os textos e traduções disponíveis on-line, dando preferência, respectivamente, para os sites: https://aquinasinstitute.org/aquinascc/ e http://www. corpusthomisticum.org/.

${ }^{48}$ Sent. IV, D. 26, q. 1. a. 1, obj. 1: "Quia jus naturale est quod natura omnia animalia docuit." Já o primeiro sed contra diz: "Sed contra est quod in principio Digestorum dicitur: jus naturale est maris et feminae conjunctio quam nos matrimonium appellamus." A despeito das duas passagens apontarem posições aparentemente antagônicas, ambas provêm da mesma fonte: D. 1.1.1.3: "Ius naturale est, quod natura omnia animalia docuit: nam ius istud non humani generis proprium, sed omnium animalium, quae in terra, quae in mari nascuntur, avium quoque commune est. Hinc descendit maris atque feminae coniunctio, quam nos matrimonium appellamus, hinc liberorum procreatio, hinc educatio: videmus etenim cetera quoque animalia, feras etiam istius iuris peritia censeri."

${ }_{49}$ Sent. IV, D. 26, q. 1. a. 1, obj. 2: "Sed matrimonium non fuit in quolibet statu hominum: quia, sicut dicit Tullius in principio Rhetor., homines a principio silvestres erant, et tunc nemo scivit proprios liberos, nec certas nuptias, in quibus matrimonium consistit. Ergo non est naturale."

${ }^{50}$ Sent. IV, D. 26, q. 1. a. q, sed contra 2: "Praeterea, in 8 Ethic., cap. 12, dicit Philosophus, quod homo magis est naturaliter conjugale animal quam politicum."
} 
inicia por distinguir dois sentidos de 'natural': a) os princípios intrínsecos que determinam causal e necessariamente o comportamento dos seres (por exemplo, mover-se para cima é natural ao fogo); b) as inclinações presentes ao ser humano, mas que necessitam da intervenção de seu livre arbítrio para que se realizem (como as virtudes naturais) ${ }^{51} \mathrm{O}$ núcleo da distinção manifesta-se na noção de razão natural (ratio naturalis), introduzida para permitir a passagem de "a natureza inclina" para "a razão natural inclina", uma vez que os atos da razão somente resultarão em ações humanas caso sejam acompanhados por decisões do livre arbítrio. A razão natural inclinaria ao matrimônio de dois modos: 1) quanto ao fim principal, é o bem da prole (bonum prolis). Não se trata apenas da prole, mas de seu bem, o que equivale a dizer que se está caracterizando não somente a tendência natural para gerar descendentes, mas apontando normativamente como o cuidado que se deve ter com a sua existência, alimentação e educação de modo a proporcionar que realizem o estado perfeito humano (ad statum perfectum humanum), a saber o estado de virtude. Esse cuidado exigiria, $\mathrm{m}$ entanto, a determinação das figuras materna e paterna e, portanto, o casamento. 2) O fim secundário seria o convívio e mútuo auxílio dos cônjuges alcançado ao viverem conjuntamente, sendo por essa razão que o ser humano seria dito naturalmente um animal político (ratione cujus dicitur homo naturaliter politicus).

O modo como a noção de ratio naturalis foi introduzida na argumentação acima poderia levar-nos a pensar que Tomás estaria se afastando das fontes romanas e privilegiando o sentido aristotélico de razão. As ambiguidades dos textos jurídicos, no entanto, não permitem uma conclusão tão nítida. Como vimos acima, Ulpiano realmente sustenta que a união entre os sexos é de direito natural e comum a todos os animais. Todavia, Tomás afirma que a natureza inclina o ser humano de uma dupla maneira, como pode ser constatado na própria definição de ser humano como animal racional. O ser humano compartilha os princípios definidores do gênero animalidade com os demais membros desse gênero e são precisamente esses princípios comuns a todos os animais que os inclinam à procriação. Entretanto, o modo particular como a inclinação genérica vai se manifestar dependerá da diferença específica e, no caso do ser humano, da racionalidade. ${ }^{52}$ Assim, ainda que a natureza incline todos os animais para a procriação, não o faz do mesmo modo. ${ }^{53}$ Além disso, não podemos perder de vista que

\footnotetext{
${ }^{51}$ Sent. IV, D. 26, q. 1. a. 1: "Alio modo dicitur naturale ad quod natura inclinat, sed mediante libero arbitrio completur, sicut actus virtutum dicuntur naturales."

${ }^{52}$ Sent. IV, D. 26, q. 1. a. 1, ad 1: "Et sicut natura generis quamvis sit una in omnibus animalibus, non tamen est eodem modo in omnibus; ita etiam non inclinat eodem modo in omnibus, sed secundum quod unicuique competit."

${ }^{53}$ Sent. IV, D. 26, q. 1. a. 1, ad 1: "Sed quantum ad primam rationem inclinat ex parte generis; unde dicit, quod filiorum procreatio communis est omnibus animalibus. Tamen ad hoc non inclinat eodem modo in omnibus animalibus (...)."
} 
a expressão ratio naturalis está igualmente presente nas fontes romanas, como vimos na caracterização de Gaio do ius gentium.

Com o segundo artigo da distinção 26, Tomás de Aquino pretende qualificar o tipo de obrigação advinda das inclinações naturais. Parece ser uma conclusão do artigo anterior a obrigação dos pais de ocuparem-se da vida e educação de seus filhos. Entretanto, se todas as inclinações naturais carregassem consigo a mesma carga de obrigatoriedade, então contrair matrimônio seria uma obrigação para todas as pessoas, inclusive para aquelas que pretendessem se dedicar à vida religiosa. A segunda objeção resume a dificuldade afirmando que se os preceitos do direito natural obrigam em todos os tempos e se o matrimônio é de direito natural, então essa seria uma obrigação natural. ${ }^{54}$ A solução proposta opta por qualificar as obrigações naturais sustentando que a natureza inclina de dois modos distintos. Por um lado, há o que é necessário para a perfeição dos seres humanos, considerando-se a perfeição de cada um dos indivíduos, ou seja, aquilo que cada pessoa deve individualmente realizar para alcançar a sua perfeição. Essas são as perfeições naturais e comuns a todos. Mas nem todas as perfeições necessitam ser tomadas distributivamente. A perfeição da multidão (multitudo) acarreta apenas que certas obrigações devam ser realizadas pelo conjunto das pessoas, sem que todas as pessoas necessitem individualmente realizá-las, mesmo porque as obrigações podem ser mutuamente excludentes em sua realização. ${ }^{55}$ Tomás recorre, nesse contexto, à noção de officium, ou seja, às diversas obrigações necessárias para a vida em comunidade. A vida em sociedade envolve a existência de diversas atividades especializadas (agricultura e edificações) e faz parte da natureza cooperativa da vida em comunidade que algumas pessoas possam se especializar e contribuir para o fim da comunidade. Dessa forma, se algumas pessoas escolhem a vida matrimonial e outros a vida contemplativa, incompatível com a primeira no dizer de Teofrasto, isso ocorre porque a natureza inclina a diversos ofícios e atos (officia et actus), dependendo do modo como a natureza é individuada nesta ou naquela pessoa. ${ }^{56}$

A distinção romana entre status e officium será a pedra basilar empregada pelo Aquinate para a caracterização do casamento como sacramento. A natureza inclina para o matrimônio buscando a realização de um certo

\footnotetext{
${ }^{54}$ Sent. IV, D. 26, q. 1. a. 2, obj. 2: "Praeterea, praecepta juris naturalis secundum omne tempus obligant. Sed matrimonium est de jure naturali, ut dictum est. Ergo, etc."

${ }_{55}$ Sent. IV, D. 26, q. 1. a. 2: "Uno modo sicut ad id quod est necessarium ad perfectionem unius; et talis inclinatio quemlibet obligat; quia naturales perfectiones omnibus sunt communes. Alio modo inclinat ad aliquid quod est necessarium ad perfectionem multitudinis: et cum multa sint hujusmodi, quorum unum impedit aliud."

${ }^{56}$ Sent. IV, D. 26, q. 1., a. 2, ad 4: "Ad quartum dicendum, quod natura humana communiter ad diversa officia et actus inclinat, ut dictum est. Sed quia est diversimode in diversis, secundum quod individuatur in hoc vel illo; unum magis inclinat ad unum illorum officiorum, alium ad aliud."
} 
bem que é variável conforme a diversidade de status dos seres humanos. Após sustentar que à variedade de status está associada a variedade de bens, Tomás pode diferenciar o status da vida antes e depois do pecado e mostrar que, mesmo antes da queda, o matrimônio fazia-se necessário, pois o bem buscado era a procriação da prole e isso era exigido independe e previamente à figura do pecado. Após a queda, no entanto, o matrimônio passa a adquirir a função de remédio contra o pecado, o que foi feito pela lei da natureza (lex naturae). Em momento posterior, passa a ser regrado pela lei mosaica. Adquire a forma de sacramento com a nova lei (nova lex) e passa a representar o mistério da união do Cristo com a Igreja. Por fim, pela lei civil (lex ciuilis) o casamento é instituído em prol da amizade e do mútuo auxílio prestados reciprocamente pelos cônjuges. Tomás designa a primeira instituição como um ofício da natureza (officium naturae) e a última como um ofício civil (officium cilitatis). Ao tratar dos impedimentos para o casamento na distinção 34 do mesmo Livro IV, o Aquinate resume o ponto nos seguintes termos:

Mas o casamento, na medida em que é um ofício da natureza (officium naturae), está fundado no direito natural; na medida em que é um sacramento, está fundado no direito divino; na medida em que é um ofício da comunidade (officium communitatis), está fundado no direito civil; e portanto, por qualquer uma das leis nomeadas uma determinada pessoa pode ser inelegível para o casamento. Também não é semelhante aos outros sacramentos, que são apenas sacramentos. E porque a lei natural recebeu diversas determinações de acordo com diversos estados (status), e a lei positiva também é variada de acordo com as diversas condições dos homens em diversos tempos; ... ${ }^{57}$

\section{Conclusão}

Quando Tomás de Aquino escreve os seus Comentários às Sentenças de Pedro Lombardo, o vocabulário a que ele emprega para caracterizar o status das pessoas é aquele que encontramos transmitido pelo Digesto e pelas Institutas. No momento em que é preciso determinar quem tem capacidade de realizar uma promessa ou firmar um compromisso religioso, Tomás recorre à estrutura da família romana e aos tipos de poderes que elas

\footnotetext{
${ }^{57}$ Sent. IV, D. 34, q. 1. A. 1, ad 4: "Matrimonium autem, inquantum est in officium naturae, statuitur lege naturae; inquantum est sacramentum, statuitur jure divino; inquantum est in officium communitatis statuitur lege civili; et ideo ex qualibet dictarum legum potest aliqua persona effici ad matrimonium illegitima. Nec est simile de aliis sacramentis, quae sunt sacramenta tantum. Et quia lex naturalis secundum diversos status recipit determinationes diversas, et jus positivum etiam variatur secundum diversas hominum conditiones in diversis temporibus; ..."
} 
possuíam no interior dessa estrutura. Basta, por exemplo, ler os artigos referentes os impedimentos acerca do matrimônio das pessoas escravizadas $^{58}$ ou acerca dos impedimentos dos votos religiosos ${ }^{59}$ para constatar o emprego de expressões jurídicas como sui iuris, servus est res domini, servitus est contra naturam, in potestate alterius, filius familas est in potestate patris. Como deve ter ficado evidenciado pelo presente artigo, Tomás de Aquino não faz exclusivamente um uso anódino da terminologia jurídica. Vale-se dela interpretando-a de modo a poder aplicá-la a outros aspectos das comunidades medievais. No presente artigo, limitamos nossa abordagem aos Comentários às Sentenças. Em uma pesquisa mais ampla, deveríamos analisar períodos posteriores da obra do Aquinate, o que nos obrigaria a considerar outras fontes, notadamente a Política de Aristóteles, e seu impacto na interpretação das relações de poder internas à estrutura familiar.

A guisa de conclusão, gostaríamos de deixar a sugestão de que a pesquisa mais ampla acabaria por deparar-se, por exemplo, na Suma de Teologia, justamente com o par conceitual que decidimos destacar em nossa abordagem: status e officium. A questão 183 da secunda secundae tem por título precisamente: Os ofícios e os estados dos homens em geral e divide-se em quatro artigos. Ainda que os textos romanos não sejam citados em abundância, o referencial teórico é o que vínhamos destacando. O primeiro artigo dessa questão versa sobre a significação de status e seu vínculo com a liberdade e escravidão. Sustenta que o termo status aponta para uma certa imobilidade não sendo, portanto, aquilo que varia facilmente, como ser rico ou pobre. Referindo-se diretamente ao que ocorre no direito civil (in iure ciuili), cita o que acontece quando alguém é privado de sua dignidade (dignitas), mas não de seu estado, pois o estado do homem (status hominis) diz respeito à obrigação da própria pessoa, enquanto é independente (sui iuris) ou dependente (alieni). ${ }^{60} \mathrm{O}$ próximo artigo continua a discussão mostrando como a distinção, que nos vimos ser forjada no interior do direito civil, passa a ser empregada para definir as estruturas internas à Igreja. A Igreja deve ser considerada como algo complexo que necessita de uma diversidade de estados e ofícios, o que é explicado por meio de três razões: a) devido à perfeição da própria Igreja; b) para a realização das atividades necessárias à Igreja; c) pela ordem que confere dignidade e beleza à Igreja.

\footnotetext{
58 Sent. IV, D. 38, q. 1. A. 1.

${ }^{59}$ Sent. IV, D. 38, q. 1. A. 1.

${ }^{60}$ S.T. II-II, Q. 183, a 1.: “Et inde est quod etiam in ipsis humanis actionibus dicitur negotium aliquem statum habere secundum ordinem propriae dispositionis, cum quadam immobilitate seu quiete. Unde et circa homines, ea quae de facili circa eos variantur et extrinseca sunt, non constituunt statum, puta quod aliquis sit dives vel pauper, in dignitate constitutus vel plebeius, vel si quid aliud est huiusmodi, unde et in iure civili dicitur quod ei qui a senatu amovetur, magis dignitas quam status aufertur. Sed solum illud videtur ad statum hominis pertinere quod respicit obligationem personae hominis, prout scilicet aliquis est sui iuris vel alieni, et hoc non ex aliqua causa levi vel de facili mutabili, sed ex aliquo permanente. Et hoc est quod pertinet ad rationem libertatis vel servitutis."
} 
Ainda na Suma de Teologia, na questão em que trata do Direito, após discutir o direito como objeto da justiça, retomar a distinção entre direito positivo e natural e tomar posição no debate entre as concepções bipartite de Gaio e tripartite de Ulpiano, Tomás aborda a distinção entre o direito paterno e o senhorial. A questão encerra com a retomada da noção de officium nos seguintes termos:

QUANTO AO $3^{0}$, deve-se dizer que todas as outras diferenças das pessoas que se encontram na cidade, têm uma relação imediata da cidade com o seu príncipe. Por isso, a elas se aplica o direito segundo a noção perfeita de justiça. Este direito se distingue, todavia, segundo a diversidade das funções (officia). Fala-se, assim, do direito militar, do direito dos magistrados ou dos sacerdotes. Não é que se trate aí de deficiência na plena realização do direito, como no caso do direito paterno ou senhorial. Mas, sim, porque a cada condição da pessoa, segundo a sua função própria (officium proprium), se deve algo de próprio. ${ }^{61}$

Em suma, mesmo após ter completamente assimilado os ensinamentos da Política de Aristóteles, o Doctor Communis continua a preservar elementos centrais do direito romano entre os conceitos que nortearão a sua compreensão da vida familiar, civil e religiosa.

Endereço do Autor:

Rua Augusto Meyer 20 - Apto. 802

Bairro Auxiliadora

90540-070 Porto Alegre - RS

alfredostorck@gmail.com

${ }^{61}$ TOMÁS DE AQUINO. Suma teológica. Vários tradutores. São Paulo: Edições Loyola Jesuítas, vol. 6, p. 54. "Ad tertium dicendum quod omnes aliae diversitates personarum quae sunt in civitate, habent immediatam relationem ad communitatem civitatis et ad principem ipsius. Et ideo ad eos est iustum secundum perfectam rationem iustitiae. Distinguitur tamen istud iustum secundum diversa officia. Unde et dicitur ius militare vel ius magistratuum aut sacerdotum, non propter defectum a simpliciter iusto, sicut dicitur ius paternum et dominativum, sed propter hoc quod unicuique conditioni personae secundum proprium officium aliquid proprium debetur." 